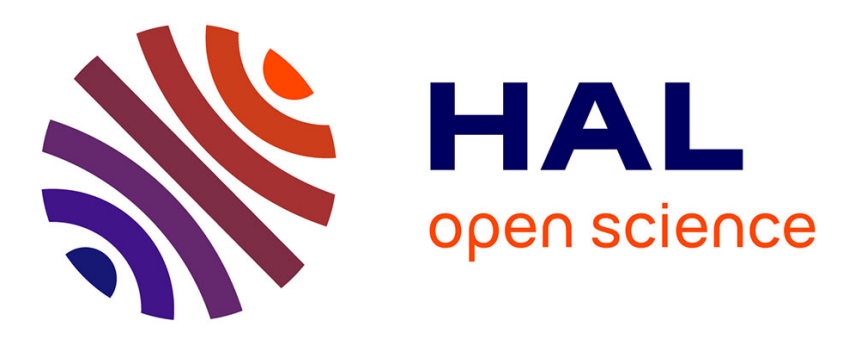

\title{
Development of Latent Fingerprints via Aryldiazonium Tetrachloroaurate Salts on Copper Surfaces: An XPS Study
}

Saeed Almheiri, Ahmad Ahmad, Benjamin Le Droumaguet, Rémy Pires, Ahmed Mohamed, Mohamed Chehimi

\section{To cite this version:}

Saeed Almheiri, Ahmad Ahmad, Benjamin Le Droumaguet, Rémy Pires, Ahmed Mohamed, et al.. Development of Latent Fingerprints via Aryldiazonium Tetrachloroaurate Salts on Copper Surfaces: An XPS Study. Langmuir, 2019, 36 (1), pp.74-83. 10.1021/acs.langmuir.9b03390 . hal-03095272

\section{HAL Id: hal-03095272 \\ https://hal.science/hal-03095272}

Submitted on 4 Jan 2021

HAL is a multi-disciplinary open access archive for the deposit and dissemination of scientific research documents, whether they are published or not. The documents may come from teaching and research institutions in France or abroad, or from public or private research centers.
L'archive ouverte pluridisciplinaire $\mathbf{H A L}$, est destinée au dépôt et à la diffusion de documents scientifiques de niveau recherche, publiés ou non, émanant des établissements d'enseignement et de recherche français ou étrangers, des laboratoires publics ou privés. 


\section{Developed Latent Fingerprints via}

\section{Aryldiazonium Tetrachloroaurate Salts on Copper Surfaces:}

\section{An XPS Study}

Saeed A. Almheiri, ${ }^{\mathrm{a}, \mathrm{b}}$ Ahmad A. L. Ahmad, ${ }^{\mathrm{c}}$ Benjamin Le Droumaguet ${ }^{\mathrm{b}}$, Rémy Pires ${ }^{\mathrm{b}}$, Ahmed A. Mohamed, ${ }^{*}, \mathrm{a}$ Mohamed M. Chehimi ${ }^{*}, \mathrm{~b}$

a. Center for Advanced Materials Research, Research Institute of Sciences and Engineering, University of Sharjah, Sharjah 27272, UAE

b. Univ Paris Est Creteil, CNRS, UMR 7182, UPEC, F-94320 Thiais, France

c. Department of Chemistry, University of Maine, Orono, ME 04469, USA

\section{Corresponding Authors}

Mohamed M. Chehimi, chehimi@icmpe.cnrs.fr

Ahmed A. Mohamed, ah.mohamed@sharjah.ac.ae

DOI: 10.1021/acs.langmuir.9b03390 


\begin{abstract}
Surface studies of developed fingerprints have aided in the elimination of criminal cases before moving to the court. The combination of X-ray photoelectron spectroscopy (XPS) with the aryldiazonium gold(III), $4-\mathrm{O}_{2} \mathrm{NC}_{6} \mathrm{H}_{4} \mathrm{~N}_{2}{ }^{+} \mathrm{AuCl}_{4}{ }^{-}$, surface modifier has shown to be a novel approach in latent fingerprint detection and development for the quantification of film elements. The robust gold-aryl film was developed on the reducing chemicals excreted in the sebaceous fingerprints without the need for external stimuli, and at lesser extent after contacting the free metal surface. The concurrent reduction of the diazonium functional group and gold(III) from $\left[\mathrm{AuCl}_{4}\right]^{-}$developed a robust gold-aryl film which showed increasing gold(0) quantity in the time range 30 to 120 min over copper coins and model flat sheets. SEM and XRD support the presence of reduced gold on the top of the latent fingerprints and the presence of $\mathrm{CuO}$ resulting from the reaction of the diazonium salt with copper metal. This research combines the quantification of deposits using XPS, the surface sensitive technique for chemical analysis, in addition to the surface imaging.
\end{abstract}

Keywords. Forensics, Diazonium Gold Salt, Copper Coins, XPS, Latent Fingerprints, Gold-Aryl Film. 


\section{Introduction}

Alongside the early detection of the developed fingerprints on various types of surfaces, many efforts were put to quantitatively determine the chemical components existing in latent fingerprints. ${ }^{1,2}$ One of such efforts includes the use of X-ray photoelectric spectroscopy (XPS). ${ }^{\mathbf{3 , 4}}$ Since the 1980s, XPS has gained momentum in forensic science in the analysis of explosives. ${ }^{\mathbf{4 - 8}}$ According to Watts, ${ }^{9}$ the use of XPS in fingerprint analysis was first recorded in 1970 by David Clark and David Briggs as an experiment performed to their local newspaper (Newcastle, England). The local newspaper at the time misunderstood that XPS may accurately track the ownership of the fingerprints in real time to catch escaping burglars. Despite this amusing misconception, Watts suggested that XPS may help identify potential suspect when characteristic materials persist on the suspect's fingerprints that may be readily transferred as well to the surface alongside with the fingerprints. An example would be the XPS peaks showing Si2p and Si2s from a sample of female fingerprints. Silicon is often used in cosmetics and skin products; thus, Si peaks may act as a potential route to identify the use of certain products by the suspect. Such profiling information from XPS can considerably reduce the suspect pool.

There are a few techniques which aided the development of forensic science and moving this emerging field from being dependent on merely qualitative to quantitative. The recent progress utilized FTIR, ${ }^{10,11}$ mass spectrometry, ${ }^{12,13}$ fluorescence, ${ }^{14,15}$ X-ray fluorescence ${ }^{12,16}$ in addition to imaging approaches. ${ }^{17}$ XPS has been introduced as surface technique for elemental analysis. $^{18-20}$

A recent report proposed an interesting method of demonstrating latent fingerprints on reactive metal surfaces using diazonium salts stabilized by tetrachloroaurate ion, $\mathrm{NO}_{2^{-}}$ 
aryldiazonium- $\mathrm{AuCl}_{4} .^{21}$ Authors used imaging techniques such as SEM, XRF and optical microscopy to visualize the change on common metals of crime scenes. It was concluded from the study that copper surface is the most successful among the three reducing metals copper, aluminum and zinc. The gold film aided to visualize the three levels of primary, secondary and tertiary fingermarks at high level of details. Reduced gold on fingerprints can be beneficial in archiving and future analysis. It is to note that poor development of the latent fingerprint was noted with aryldiazonium tetrafluoroborate $\left(4-\mathrm{O}_{2} \mathrm{NC}_{6} \mathrm{H}_{4} \mathrm{~N}_{2}{ }^{+} \mathrm{BF}_{4}^{-}\right)$, on the one hand, and poor contrast images with scattered minor deposits slowly occurred after an elapsed time of $24 \mathrm{~h}$ after deposition of the reactive aryldiazonium solution. Despite the successful use of aryldiazonium tetrachloroaurate for the visualization of the fingerprints, the recently published paper focused mainly on imaging techniques. As the demonstration of fingerprints using diazonium salts on easily reactive materials (e.g. copper) is a surface chemical reaction, we anticipated that the combination of diazonium chemistry and XPS would be an original and unique method to investigate. Indeed, it is well know that aryldiazonium salts reduce spontaneously on copper ${ }^{22}$ and for the demonstration of proof of concept, this would be an ideal combination to track by XPS surface modification of copper coins (Euro cents) resulting from diazonium chemistry. The rationale for this motivation is that elsewhere, the surface analyses might take requires heat ${ }^{23}$ or application of an electrical potential to enhance visualization of the said fingerprints. ${ }^{\mathbf{2 4}}$ Herein, and as some of us have previously reported, the latent fingerprints are demonstrated spontaneously without any physico-chemical assitance, which facilitates the whole study and subsequent XPS analysis.

In this study, we have cleaned copper coins and model flat copper sheets and affixed fingerprints of a donor. The fingerprints were developed with aryldiazonium tetrachloroaurate 
aqueous solution for $1 \mathrm{~h}$. After washing, the copper coins and flat surfaces were analyzed by XPS. We will tackle two main aspects: (i) surface chemistry of aryldiazonium tetrafluoroborate salts, and (ii) XPS analysis of the positive and negative parts of the developed parts of the fingerprint on copper coin and model flat surface (Figure S1). We will then concentrate on our results of the selective binding phenomena between diazonium and fingerprints on top of copper metal. As our work is focused on fingerprints within the framework of forensic science, we have chosen to conduct surface chemical reactions on copper coins (Euro cents) in order to replicate a "real world" scenario. Some specific experiments have also been conducted on model, flat copper plate.

\section{Experimental Section}

Reagents. The reagents were used without any further purification: hydrochloric acid (Carlo Erba, 37\%), nitric acid (Carlo Erba, 65\%), 4-nitroaniline (Sigma-Aldrich, $\geq 99 \%$ ) and sodium nitrite (Sigma-Aldrich, $\geq 97 \%$ ).

Synthesis and characterization of $4-\mathbf{O}_{2} \mathbf{N C}_{6} \mathbf{H}_{4} \mathbf{N}_{2}{ }^{+} \mathbf{A u C l}_{4}{ }_{4}^{-}$. 4-Nitroaniline $(0.691 \mathrm{~g}, 5.0 \mathrm{mmol})$ was dissolved in $28.0 \mathrm{~mL}$ of $6.0 \mathrm{M} \mathrm{HCl}$ and the solution was cooled to $4.0^{\circ} \mathrm{C}$. Afterwards, $\mathrm{NaNO}_{2}(0.345 \mathrm{~g}, 5.0 \mathrm{mmol})$ was dissolved in $5.0 \mathrm{~mL}$ of deionized water and added to the previous solution after it was cooled to $4.0^{\circ} \mathrm{C}$. The reaction mixture was stirred for $30 \mathrm{~min}$ at 4.0 ${ }^{\circ} \mathrm{C}$. Next, $\mathrm{H}\left[\mathrm{AuCl}_{4}\right]$ was dissolved in $10.0 \mathrm{~mL}$ of water at $4.0{ }^{\circ} \mathrm{C}$ and added dropwise to the previous reaction mixture and was stirred for an additional $1 \mathrm{~h}$ at room temperature. The precipitate was recovered by suction filtration and dried to yield a bright yellow precipitate $(1.076 \mathrm{~g}, 44.1 \%)$. Finally, the product was dissolved in water to form a $0.001 \mathrm{M}$ solution which

was used in all fingerprint development studies. The salt was characterized by ${ }^{1} \mathrm{H}$ NMR 
$\left(\left(\mathrm{CD}_{3}\right)_{2} \mathrm{CO}, 298 \mathrm{~K}\right): \delta(\mathrm{ppm}) 9.28\left(\mathrm{~d},{ }^{3} \mathrm{~J}=8.8 \mathrm{~Hz}\right), 8.90\left(\mathrm{~d},{ }^{3} \mathrm{~J}=8.8 \mathrm{~Hz}\right) ;{ }^{13} \mathrm{C}$ NMR $\left(\left(\mathrm{CD}_{3}\right)_{2} \mathrm{CO}\right.$, 298K): $\delta$ (ppm) 155.05, 135.65, 127.46, 122.12; and main ATR-FTIR bands at $v_{\max }\left(\mathrm{cm}^{-1}\right) 2280$ $\left(\mathrm{N} \equiv \mathrm{N}\right.$ stretch), $1537\left(\mathrm{NO}_{2}\right.$ asymmetrical stretch), 1349 (symmetrical stretch of $\left.\mathrm{NO}_{2}\right), 1315(\mathrm{C}-\mathrm{H}$ in plane deformation).

Deposition of $4-\mathrm{O}_{2} \mathbf{N C}_{6} \mathbf{H}_{4} \mathbf{N}_{2}{ }^{+} \mathbf{A u C l}_{4}{ }^{-}$on copper coins. Copper coins $(€ 0.20)$ surfaces were prepared by cleaning with distilled white vinegar $(\sim 6-8 \%)$ and table salt to remove the oxides, sonification to remove any dirt and then washed with absolute ethanol. The following samples were prepared for XPS analysis: $\mathrm{Cu}$ coin (clean); $0.001 \mathrm{M} \mathrm{4-O}_{2} \mathrm{NC}_{6} \mathrm{H}_{4} \mathrm{~N}_{2}{ }^{+} \mathrm{AuCl}_{4}{ }^{-}$solution was dropped using a dropper on $\mathrm{Cu}$ coin+fingerprint $(1 \mathrm{~h})$. The surface was then washed gently with deionized water until the excess salt was completely washed away and dried. The sample formed a film just enough to cover the suspected area.

Deposition of 4- $\mathrm{O}_{2} \mathrm{NC}_{6} \mathrm{H}_{4} \mathbf{N}_{2}{ }^{+} \mathrm{AuCl}_{4}{ }^{-}$on copper sheets. Three copper sheets $\left(1 \mathrm{~cm}^{2}\right)$, and one copper slit $\left(5 \times 1 \mathrm{~cm}^{2}\right)$ were prepared by cleaning with distilled white vinegar and table salt to remove the oxides, sonification to remove any dirt and then washed with absolute ethanol. The following samples were prepared for XPS analysis: $\mathrm{Cu}$ sheet (clean); $\mathrm{Cu}$ sheet+fingerprint; $\mathrm{Cu}$ slit was immersed partly $\left(1 \times 1 \mathrm{~cm}^{2}\right)$ for $30 \mathrm{~min}$. The slit was then immersed further, and the process was repeated for a total of $2 \mathrm{~h}$, resulting in a surface with multiple layers of diazonium salt (clean, immersion for 30, 60, 90, and $120 \mathrm{~min}$ ). The $0.001 \mathrm{M} 4-\mathrm{O}_{2} \mathrm{NC}_{6} \mathrm{H}_{4} \mathrm{~N}_{2}{ }^{+} \mathrm{AuCl}_{4}{ }^{-}$solution was dropped using a dropper on each of the prepared surfaces: $\mathrm{Cu}$ sheet+fingerprint $(2 \mathrm{~h})$. The surfaces were then washed gently with deionized water until the excess salt was completely washed away and dried. The samples formed a film just enough to cover the suspected area. 
Characterization. Infrared spectra were recorded using a Nicolet Magna-IR 550 spectrometer in the attenuated total reflection (ATR-FTIR) mode in the $4000-450 \mathrm{~cm}^{-1}$ range.

XPS spectra were recorded using a K Alpha apparatus (Thermo) fitted with a monochromatic Al $\mathrm{K} \alpha \mathrm{X}$-ray source (spot size: $100 \mu \mathrm{m}$ ). The pass energy was set to 200 and $80 \mathrm{eV}$ for the survey spectra and the narrow regions, respectively. The composition was determined using the manufacturer sensitivity factors. The copper coins and the model flat samples were mounted on the sample holder and clipped (Figure S2). The size of the microfocused beam was set to 100 $\mu \mathrm{m}$, sufficiently low to analyze different parts of the coins, or the flat samples. Where reaction with diazonium occurred, black spots could be analyzed (Figure S3a). Also, the fingerprints showing alternating dark and light lines could individually be analyzed (Figure S3b).

NMR spectra were recorded using a Bruker Avance II spectrometer operating at a resonance frequency of 400 and $100 \mathrm{MHz}$, respectively. For ${ }^{1} \mathrm{H}$ NMR analysis, $\left(\mathrm{CD}_{3}\right)_{2} \mathrm{CO}$ was used as a solvent and internal standard. SEM investigations were performed using a Carl Zeiss MERLIN field emission-scanning electron microscope (FE-SEM). In order to reveal alternating section in composition of the surface, backscattered electrons (BSE) were collected and imaged. Energy dispersive X-ray analysis (EDS) were performed using a X-Max silicon drift detector from Oxford Instruments coupled with AZtec operating system.

\section{Results and Discussion}

\subsection{Rationale and procedure for visualization of fingerprints using aryldiazonium tetrachloroaurate salt}


In the recent years, aryldiazonium salts of tosylates, ${ }^{\mathbf{2 5}}$ triflates ${ }^{\mathbf{2 6}}$ and tetrachloroaurate ${ }^{\mathbf{2 7}, 28}$ series emerged as very stable and safe, as they could be stored at room temperature; they are even stable up to $80-100{ }^{\circ} \mathrm{C}$, triflates could be stable after decades as has just been claimed. ${ }^{\mathbf{2 6}}$ This is a tremendous progress in the chemistry of diazonium salts. Whilst most of diazonium salts are soluble in aqueous media and react with surfaces to form surface-aryl interfacial bonds, what makes the tetrachloroaurate series unique is that the reduction of the salt affects both the diazonium cation and $\mathrm{AuCl}_{4}{ }^{-}$. If the reduction is conducted in solution, one obtains gold nanoparticles grafted with aryl functional groups. However, if the reduction is conducted in the presence of a substrate, one is faced with a more complex situation in the sense that both gold and aryl groups react and deposit on the surface but not necessarily a film of gold-aryl nanoparticles is formed. This is what we will investigate in depth in the following sections. One way to contribute to the study and visualization of fingerprints is by combining diazonium salts and XPS. Diazonium salts react spontaneously on surfaces with reducing power; this is why we have selected copper coins (2 euro cents, unless otherwise stated). The choice of the nitrobenzenediazonium cation lies in the ability to provide a unique elemental marker for the aryl groups after reaction of the parent diazonium salt with the surface. As a matter of fact, $\mathrm{NO}_{2}$ group is featured by N1s at $\sim 406 \mathrm{eV}$. This unique marker permitted to Pinson and co-workers in 1992 to demonstrate that passivation of electrodes was due to nitrophenyl groups. ${ }^{29}$ In this sense, XPS is a very surface sensitive technique and could be employed in this work with a microfocused beam, so that we could analyze both the positive and negative fingerprints after reaction of a aryldiazonium tetrachloroaurate aqueous solution with cleaned copper coins and model flat samples.

\subsection{Synthesis and characterization of $4-\mathrm{O}_{2} \mathrm{NC}_{6} \mathrm{H}_{4} \mathrm{~N}_{2}{ }^{+} \mathrm{AuCl}_{4}{ }^{-}$salt.}


Aryldiazonium tetrachloroaurate salt was synthesized for the purpose of this study because it gives a specific $\mathrm{NO}_{2} \mathrm{~N} 1 \mathrm{~s}$ peak in addition to Au4f from metallic gold obtained by reduction at the copper surface. These features are well distinguished in XPS from Cu2p peak due to the underlying copper coin or plate. ${ }^{1} \mathrm{H}$ NMR characterization in deuterated acetone showed two distinct doublet of doublet peaks at $\delta=8.90 \mathrm{ppm}$ and $\delta=9.28 \mathrm{ppm}$, each with clear $\mathrm{H}$ integration of $2 \mathrm{H}$. The first peak at $\delta=8.90 \mathrm{ppm}$ appears as a strong doublet which corresponds to the hydrogen atoms closer to $\mathrm{N} \equiv \mathrm{N}^{+}$. The second strong doublet at $\delta=9.28 \mathrm{ppm}$ corresponds to the hydrogen atoms closer to $\mathrm{NO}_{2}$. It should also be noted that at the time of the analysis, two short peaks started to form at $\delta=8.00 \mathrm{ppm}$ and $\delta=6.75 \mathrm{ppm}$, indicative of the reducible nature of diazonium salts. The analysis was redone after two days and the two peaks were stronger and sharper. This observation serves as a further evidence of the low shelf-life nature of the diazonium salt in solution at room temperature. FTIR spectra showed three significant peaks. First peak at $2280 \mathrm{~cm}^{-1}$ corresponds to the $\mathrm{N} \equiv \mathrm{N}^{+}$(strong) stretching frequency. The second peak at $1600 \mathrm{~cm}^{-1}$ corresponds to the aromatic $\mathrm{C}=\mathrm{C}$ (weak) stretching frequency. The third peak came at $1400 \mathrm{~cm}^{-1}$ corresponds to the $\mathrm{C}-\mathrm{N}$ (medium-weak) stretching frequency. 

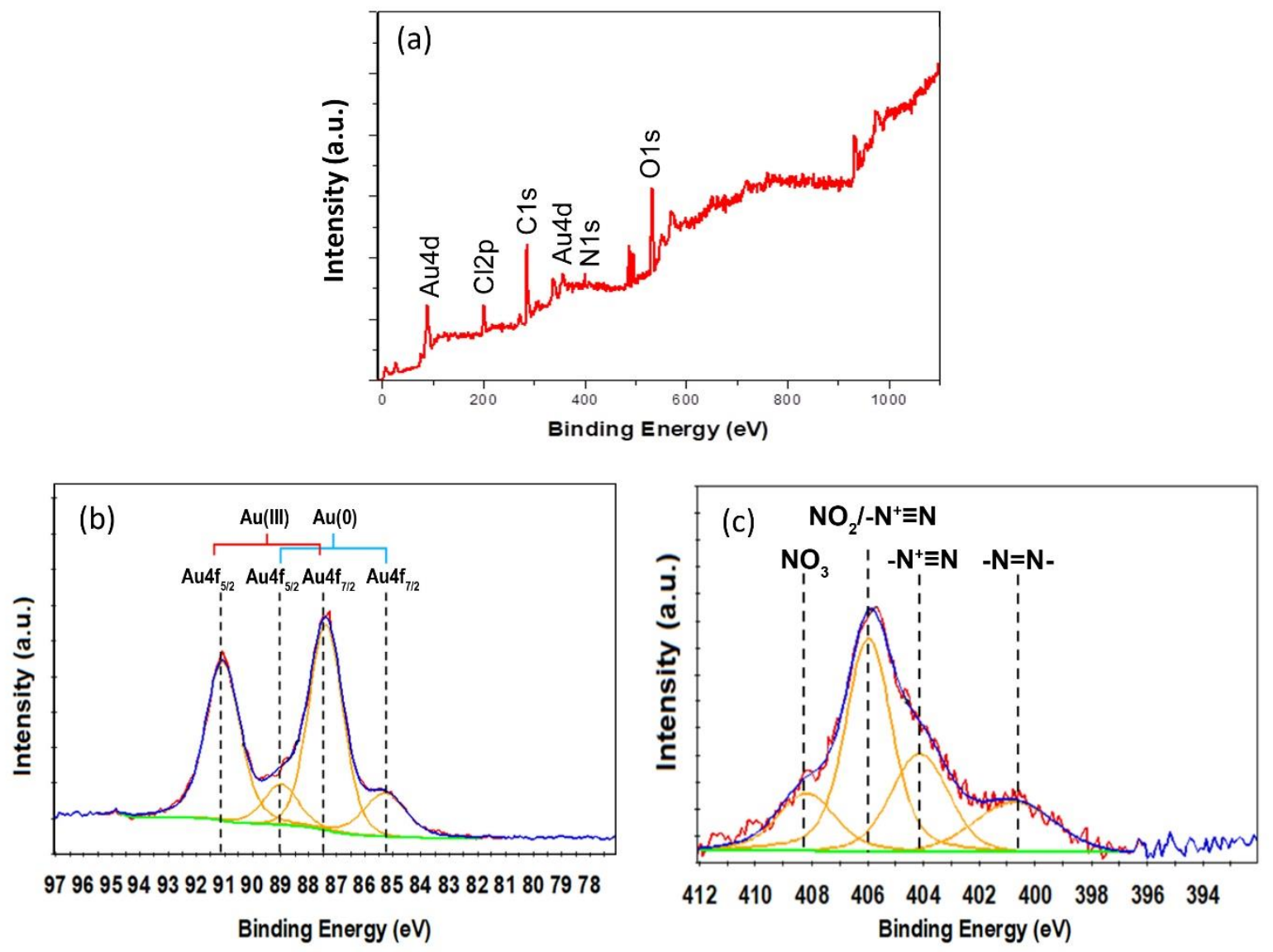

Figure 1. (a) XPS survey scan of $4-\mathrm{O}_{2} \mathrm{NC}_{6} \mathrm{H}_{4} \mathrm{~N}_{2}{ }^{+} \mathrm{AuCl}_{4}{ }^{-}$, (b) peak-fitted high-resolution $\mathrm{Au} 4 \mathrm{f}$ spectra, (c) N1s.

XPS spectra of 4- $\mathrm{O}_{2} \mathrm{NC}_{6} \mathrm{H}_{4} \mathrm{~N}_{2}{ }^{+} \mathrm{AuCl}_{4}{ }^{-}$(Figure 1) displays high resolution Au4f and N1s (Figure $1 \mathrm{~b}$ and $1 \mathrm{c}$, respectively); Au4f has two doublets assigned to $4 \mathrm{f}_{7 / 2}$ and $4 \mathrm{f}_{5 / 2}$ in the $4 / 3$ ratios, assigned to $\mathrm{Au}(0)(85$ and $89 \mathrm{eV})$ and $\mathrm{Au}(\mathrm{III})(87 \mathrm{and} 91 \mathrm{eV})$, respectively. The N1s peak is fitted with four components centered at 400.7, 404.1, 406.0 and $408.2 \mathrm{eV}$ assigned to reduced nitrogen species, neutral $\mathrm{N}_{\text {in }} \mathrm{N}_{2}{ }^{+}$group, $\mathrm{NO}_{2}$, and possibly $\mathrm{NO}_{3}{ }^{-}$contamination that might occur during the synthesis of $\mathrm{H}\left[\mathrm{AuCl}_{4}\right]$ using aqua regia. Although the diazonium product was thoroughly washed, we have invariably observed nitrates, nevertheless at low extent. The peak at $400.7 \mathrm{eV}$ arises from the in-situ X-ray induced reduction of the salt during XPS analysis and 
could be assigned to $-\mathrm{N}=\mathrm{N}$ - species. The peak at $406 \mathrm{eV}$ combines $\mathrm{NO}_{2}$ from the nitrobenzene and the positively charged $\mathrm{N}$ in the $\mathrm{N}_{2}^{+}$group.

\subsection{XPS analysis of surfaces developed by fingerprints}

3.3.1. Surface study on copper coins. A sample consisting of a copper coin $(2 €$ cents) with diazonium and fingerprints was analyzed using XPS as a means of a preliminary assessment (Figure 2). Fingerprint samples from 12 different areas of the right thumb were collected after hand washing with soap, thorough tap water rinsing and hand drying. The composition of the deposited materials on the copper surface is summarized in Table S1. Cu2p $\mathrm{p}_{3 / 2}$ (avg. $932.5 \pm 0.17$ $\mathrm{eV}$ corresponds to the copper coin, whereas $\mathrm{Au} 4 \mathrm{f}_{7 / 2}$ (avg. $84.2 \pm 0.02 \mathrm{eV}$ ) corresponds to gold deposits by spontaneous, in situ reduction of the aryldiazonium tetrachloroaurate salt. As shown in Figure $2 b$, the area under the curve of each position fluctuates as one moves from fingerprint to non-fingerprint region, these data initially showcase the selectivity nature of diazonium towards the fingerprint region. N1s region has two main peaks: one at (avg. $399.9 \pm 0.13 \mathrm{eV}$ ), assigned to (-N=N-) from the aryl functional groups within the aryl layer and the fingerprints, and (avg. $406.0 \pm 0.07 \mathrm{eV}$ ), assigned to the $\mathrm{NO}_{2}$ group from the diazonium. The $\mathrm{N} 1 \mathrm{~s}$ region thus shows that the diazonium cation has been reduced and this region is left only with two main components from azo and $\mathrm{NO}_{2}$ groups, and disappearance of diazonium $\mathrm{N} 1 \mathrm{~s}$ signals. Cu2p XPS spectra shows (Figure 2a) the relatively low atomic percentage because, compared to cleaned coins, the copper is attenuated by both the fingerprint and the aryl/gold deposits. 

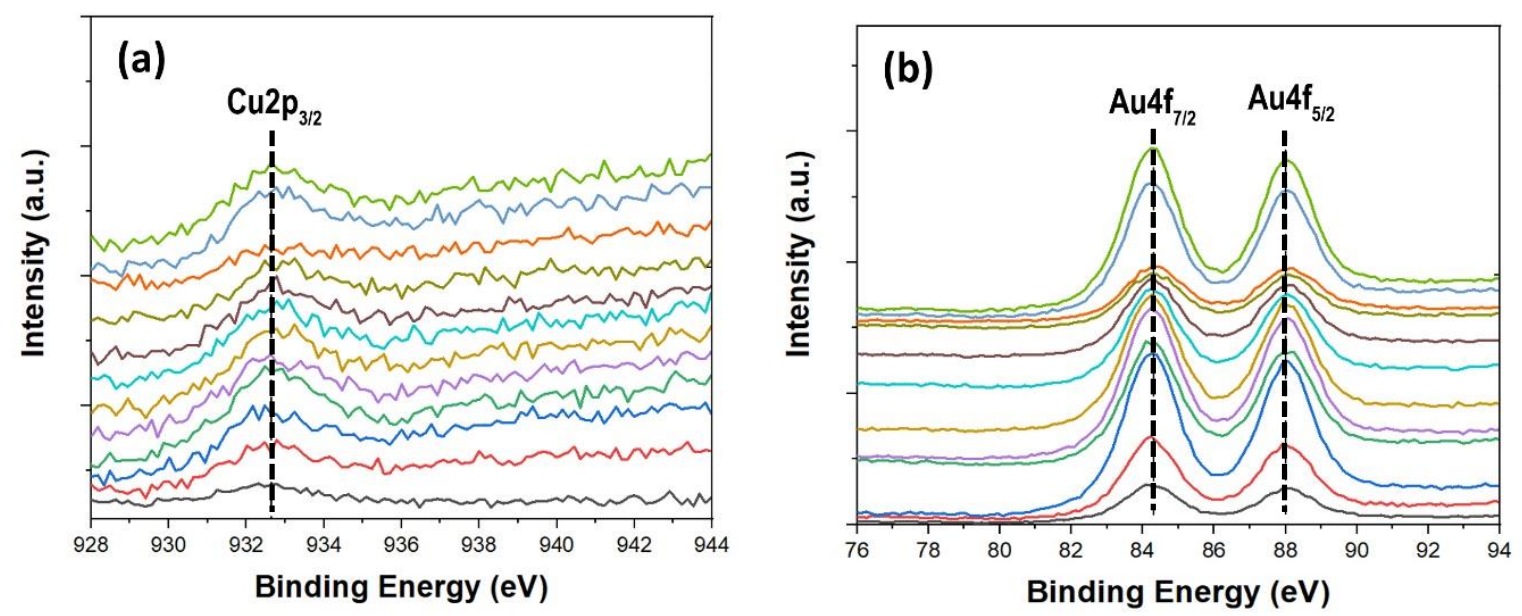

Figure 2. (a) High-resolution $\mathrm{Cu} 2 \mathrm{p}$, (b) Au4f spectra of fingerprint and $4-\mathrm{O}_{2} \mathrm{NC}_{6} \mathrm{H}_{4} \mathrm{~N}_{2}{ }^{+} \mathrm{AuCl}_{4}{ }^{-}$ treated copper coin on 12 different areas.

3.3.2. Surface study on model copper sheets. Recently, Lafi. et al. ${ }^{\mathbf{3 0}}$ discussed a phenomenon that occurs when applying aryldiazonium salt solution on a metal surface for a prolonged period. The authors found that the salt solution may further react with the metal after initially binds with the fingerprint. As a result, the whole area of metal covered with the solution turned dark instead of the predicted appearance of observable dark print of the fingerprints. Thus, we were interested in investigating the driving force behind this phenomenon. Towards this end, four samples of copper sheets were treated with the aryldiazonium gold salt, each with different treatment time of 30, 60, 90 and 120 min. The samples were subsequently characterized using XPS (Figure 3 and Table 1). As reported in Table 1, the relative atomic percentage of Au (computed using Au $4 \mathrm{f}$ doublet with $\mathrm{Au} 4 \mathrm{f}_{7 / 2}$ at $\sim 84 \mathrm{eV}$ due to $\mathrm{Au}(0)$ ) increases with treatment time (Figure $3 \mathrm{~b}$ ). This is believed to be normal due to the natural tendency of Au deposition as the solution reacts with the metal for a longer period. What seems to be unusual, the relative atomic percentage of copper (computed using $\mathrm{Cu} 2 \mathrm{p}_{3 / 2}$ at $932.5 \mathrm{eV}$ ) also increases as the treatment time increases (Figure 3c). 
This is surprising because it was expected that copper should have been covered by more deposits as time elapses, leading to less relative atomic percentage. Instead, the opposite case seems to persist, which indicates that there may be diffusion of copper species towards the surface.
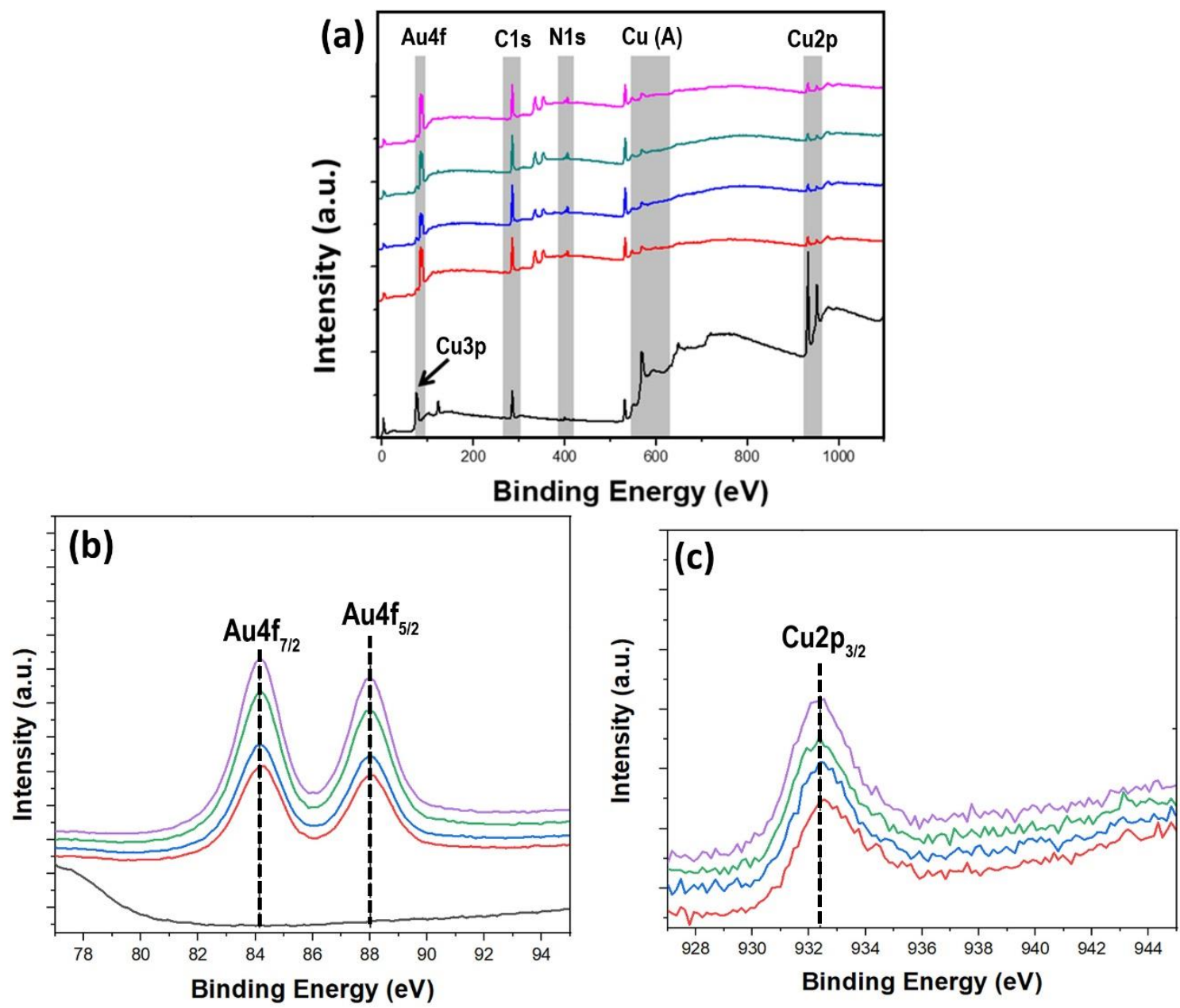

Figure 3. (a) XPS survey scan of $4-\mathrm{O}_{2} \mathrm{NC}_{6} \mathrm{H}_{4} \mathrm{~N}_{2}{ }^{+} \mathrm{AuCl}_{4}{ }^{-}$on copper sheet at multiple time increments, (black) clean $\mathrm{Cu}$, (red) after $30 \mathrm{~min}$, (blue) after $60 \mathrm{~min}$, (green) after $90 \mathrm{~min}$, and (violet) after 120 min, (b) high-resolution Au4f spectra, (c) Cu2p peak. 
Table 1. Elemental composition of copper sheet at different time increments.

\begin{tabular}{|c|c|c|c|c|c|c|}
\hline Material & & C 1s & $\mathrm{NO}_{2}$ & $-\mathrm{N}=\mathrm{N}-$ & $\mathrm{Cu} 2 \mathrm{p}_{3 / 2}$ & Au $4 f$ \\
\hline \multirow{2}{*}{$\mathrm{Cu}$ slit (Clean) } & Peak BE & 285.1 & 408.0 & 400.0 & 932.6 & 90.7 \\
\hline & Atomic $\%$ & 74.1 & 0.4 & 4.9 & 20.6 & 0.0 \\
\hline \multirow{2}{*}{$\begin{array}{l}\text { 4- } \mathrm{O}_{2} \mathrm{NC}_{6} \mathrm{H}_{4} \mathrm{~N}_{2}{ }^{+} \mathrm{AuCl}_{4}{ }^{-} \text {on } \mathrm{Cu} \\
\text { slit }(30 \mathrm{~min})\end{array}$} & Peak BE & 285.0 & 406.1 & 400.2 & 932.5 & 84.2 \\
\hline & Atomic $\%$ & 84.6 & 6.9 & 3.3 & 1.4 & 3.9 \\
\hline \multirow{2}{*}{$\begin{array}{l}4-\mathrm{O}_{2} \mathrm{NC}_{6} \mathrm{H}_{4} \mathrm{~N}_{2}^{+} \mathrm{AuCl}_{4}^{-} \text {on } \mathrm{Cu} \\
\text { slit }(60 \mathrm{~min})\end{array}$} & Peak BE & 285.0 & 406.1 & 400.1 & 932.4 & 84.1 \\
\hline & Atomic $\%$ & 83.6 & 7.2 & 3.5 & 1.4 & 4.3 \\
\hline \multirow{2}{*}{$\begin{array}{l}4-\mathrm{O}_{2} \mathrm{NC}_{6} \mathrm{H}_{4} \mathrm{~N}_{2}^{+} \mathrm{AuCl}_{4}^{-} \text {on } \mathrm{Cu} \\
\text { slit }(90 \mathrm{~min})\end{array}$} & Peak BE & 284.9 & 406.0 & 400.2 & 932.2 & 84.2 \\
\hline & Atomic $\%$ & 82.2 & 6.7 & 3.1 & 1.6 & 6.3 \\
\hline \multirow{2}{*}{$\begin{array}{l}4-\mathrm{O}_{2} \mathrm{NC}_{6} \mathrm{H}_{4} \mathrm{~N}_{2}^{+} \mathrm{AuCl}_{4}^{-} \text {on } \mathrm{Cu} \\
\text { slit }(120 \mathrm{~min})\end{array}$} & Peak BE & 284.9 & 406.0 & 400.1 & 932.3 & 84.1 \\
\hline & Atomic \% & 80.6 & 6.1 & 3.8 & 2.0 & 7.6 \\
\hline
\end{tabular}

To further investigate the products of the interfacial reaction between the diazonium tetrachloroaurate and copper, we have closely inspected the narrow $\mathrm{Cu} 2 \mathrm{p}$ copper region and have taken advantage of the method devised by Biesinger ${ }^{31}$ to deduce $\mathrm{Cu}(\mathrm{II})$ from the $\mathrm{Cu} 2 \mathrm{p}$ doublet. According to Biesinger, the $\mathrm{Cu}(0+\mathrm{I}) / \mathrm{Cu}(\mathrm{II})$ ratios for samples containing a mixture of $\mathrm{Cu}(0+\mathrm{I})$ and $\mathrm{Cu}(\mathrm{II})$ rely on estimation of the main peak/shake-up peak areas $\left(\mathrm{A}_{1 \mathrm{~s}} / \mathrm{B}_{\mathrm{s}}\right)$ for a $100 \%$ pure $\mathrm{Cu}$ (II) sample (Figure 4a). With a reliable value of $\mathrm{A} 1 \mathrm{~s} / \mathrm{Bs}$ obtained for $\mathrm{CuO}$ (Table 2), the relative concentrations of $\mathrm{Cu}(0)$ and $\mathrm{Cu}(\mathrm{II})$ species present on the surface that contain both species (Figure 4b) can be obtained using Equations 1 and 2

$$
\begin{aligned}
& \% \operatorname{Cu}(0+I)=\frac{A-\left(\frac{A_{1 s}}{B_{s}}\right) B}{A+B} \times 100 \% \\
& \% \operatorname{Cu}(I I)=\frac{B\left(1+\left(\frac{A_{1 s}}{B_{s}}\right)\right)}{A+B} \times 100 \%
\end{aligned}
$$

where $\mathrm{A}$ is the total area of the main peak and B is the area of the shake-up peak of the sample. 

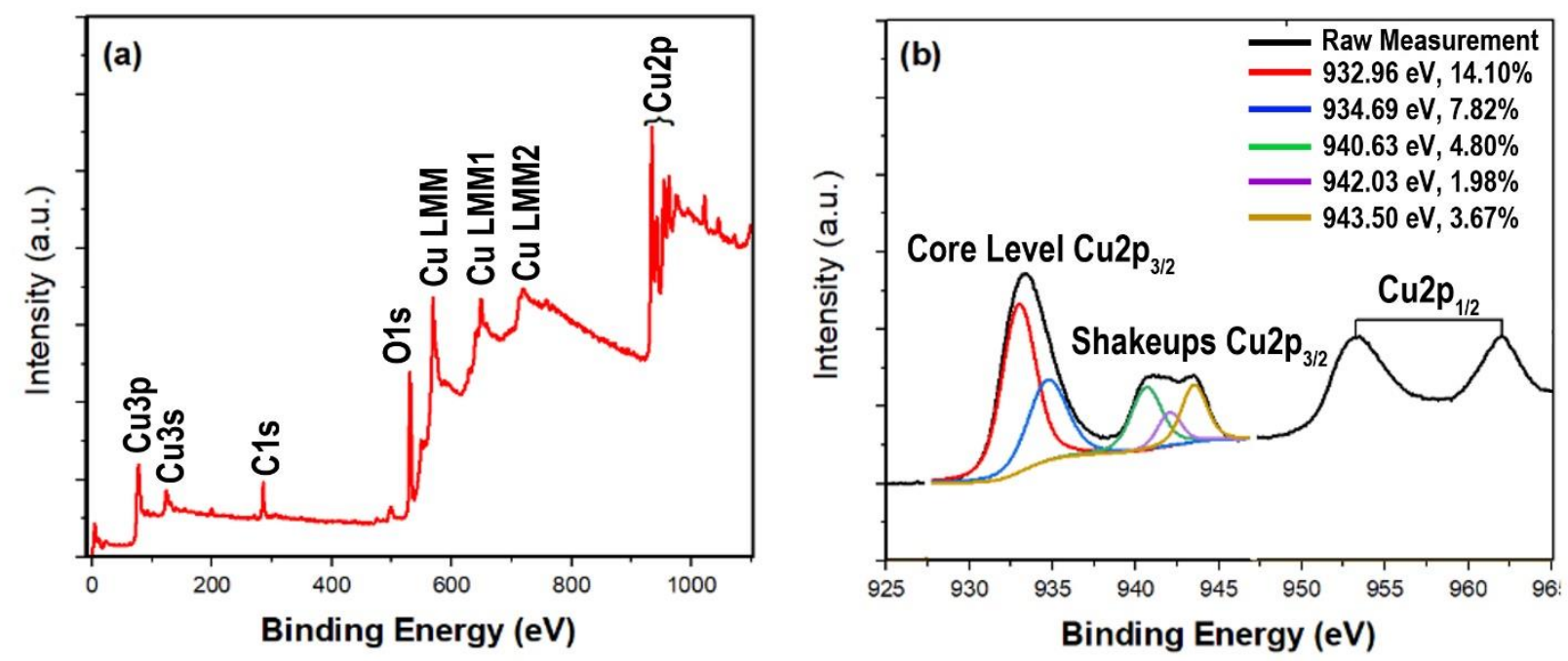

Figure 4. (a) XPS survey scan of a pure $\mathrm{CuO}$ sample, (b) peak-fitted high-resolution $\mathrm{Cu} 2 \mathrm{p}$ spectrum.

Table 2. Tabular representation of XPS data of a pure $\mathrm{CuO}$ sample (top) and ratio of the main peak/shake-up peak areas (A1s/Bs) for a 100\% pure $\mathrm{Cu}(\mathrm{II})$ sample (bottom).

\begin{tabular}{|c|c|c|}
\hline Name & Peak BE & Atomic \% \\
\hline $\mathrm{C} 1 \mathrm{~s}$ & 284.6 & 14.7 \\
\hline $\mathrm{C} 1 \mathrm{~s} \mathrm{~B}$ & 285.8 & 2.13 \\
\hline $\mathrm{C} 1 \mathrm{~s} \mathrm{C}$ & 287.53 & 1.33 \\
\hline $\mathrm{C} 1 \mathrm{~s} \mathrm{D}$ & 288.8 & 1.51 \\
\hline $\mathrm{Cu} 2 \mathrm{p}_{3 / 2}$ & 933.0 & 14.1 \\
\hline $\mathrm{Cu} 2 \mathrm{p}_{3 / 2} \mathrm{~B}$ & 934.7 & 7.82 \\
\hline $\mathrm{Cu} 2 \mathrm{p}_{3 / 2}$ (Shake-up) & 940.6 & 4.8 \\
\hline $\mathrm{Cu} 2 \mathrm{p}_{3 / 2}$ (Shake-up) B & 942.0 & 1.98 \\
\hline $\mathrm{Cu} 2 \mathrm{p}_{3 / 2}$ (Shake-up) C & 943.5 & 3.67 \\
\hline $\mathrm{Cu} \mathrm{A}$ & 568.5 & 0.0 \\
\hline $\mathrm{O} 1 \mathrm{~s}(\mathrm{CuO})$ & 529.4 & 29.7 \\
\hline O1s B & 531.3 & 14.8 \\
\hline $\mathrm{O} 1 \mathrm{~s} \mathrm{C}$ & 532.9 & 3.42 \\
\hline A1 & B1s & A1/B1s \\
\hline $\mathrm{Cu} 2 \mathrm{p}_{3 / 2}$ & $\mathrm{Cu} 2 \mathrm{p}_{3 / 2}(\mathrm{SH})$ & $\mathrm{Cu} 2 \mathrm{p}_{3 / 2} / \mathrm{Cu} 2 \mathrm{p}_{3 / 2}(\mathrm{SH})$ \\
\hline 191643.74 & 90567.96 & 2.116 \\
\hline
\end{tabular}


Next, a sample of a copper sheet treated with fingerprint and diazonium salt was analyzed (Figure 5 and Table S2). The reaction of the diazonium aqueous solution with copper yields positive dark lines after only 15-20 minutes, and bubbles are visible between the fingerprint lines (Figure 5e). As detailed in the Experimental section, $100 \mu \mathrm{m}$ spot size was used in order to analyze the dark and the light lines without any interference. An XPS spectra was collected from four different areas of the now-visible fingerprint sample (P2D and P4D: fingerprint area, P1L and P3L: non-fingerprint area), it was easy to differentiate the fingerprint (D for dark) side and the non-fingerprint (L for light) side of the copper sample by looking at the survey scan and observing the shape of the background in the range 700-900 eV (Figure 5). The composition of materials on the sample surfaces are summarized in Table S2.

Remarkably Au4d $\mathrm{d}_{5 / 2}$ (Figure 5d), centered at $335.1 \mathrm{eV}$, accounts for metallic state of gold and thus a reductive process affecting $\left[\mathrm{AuCl}_{4}\right]^{-}$anions. ${ }^{32}$ Similarly, Figure $5 \mathrm{c}$ shows only two peaks for nitrogen, one centered at $400 \mathrm{eV}$ and one at $406 \mathrm{eV}$ assigned to $-\mathrm{N}=\mathrm{N}$ - within the aryl layer and $\mathrm{NO}_{2}$, respectively. Therefore, we no longer observe the components due to $\mathrm{N} 1 \mathrm{~s}$ from the diazonium group $\mathrm{N}_{2}^{+}$. This accounts for the spontaneous reduction of the diazonium cation on copper. These XPS results parallel the direct observation of bubbles (Figure 5e) when a drop of diazonium solution is gently deposited on copper with or without fingerprint. 

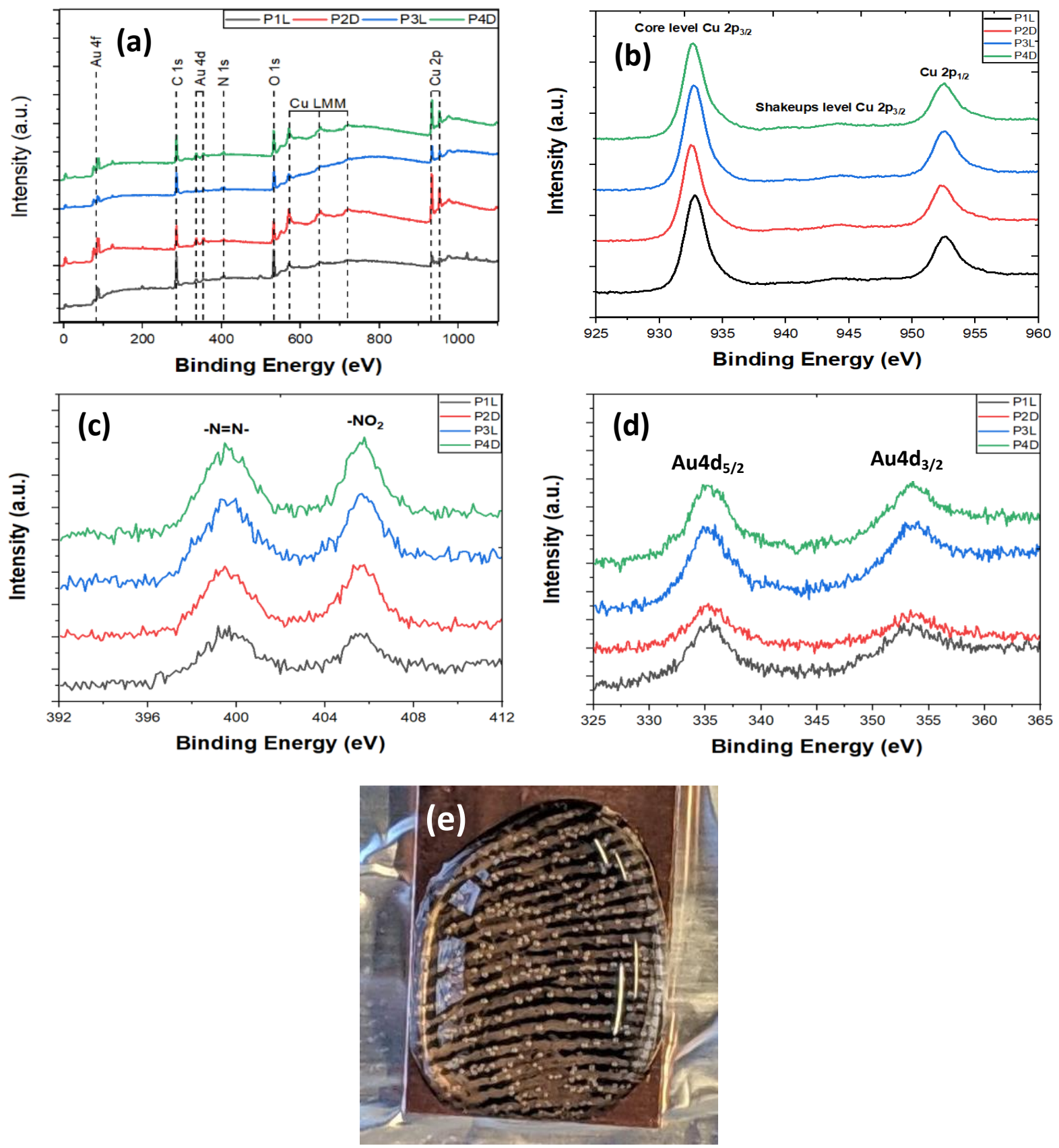

Figure 5. (a) XPS survey scan of fingerprint and $4-\mathrm{O}_{2} \mathrm{NC}_{6} \mathrm{H}_{4} \mathrm{~N}_{2}{ }^{+} \mathrm{AuCl}_{4}{ }^{-}$-treated copper sheet on four different areas, (b) high-resolution $\mathrm{Cu} 2 \mathrm{p}$, (c) N1s, (d) Au4d spectra, (e) Latent fingerprint demonstration using diazonium solution on a copper sheet. Bubbles correspond to the release of $\mathrm{N}_{2}$ due to the spontaneous reduction of diazonium cation. 


\subsection{Scanning electron microscopy of latent fingerprint after reaction with aryldiazonium tetrachloroaurate}

Further SEM images display the morphology of the surfaces (Figures 6 and 7). The SEM images of non-fingerprint area (Figure 6a) show minor gold nanoclustering (Figure 6b, c, f) on top of copper metal (Figure 6d, e). Fingerprint area investigated using EDS (Figure 7a) shows an interesting composition of what seems to be $\mathrm{CuO}$ (Figure $7 \mathrm{~b}, \mathrm{O}=34.0 \% \mathrm{Cu}=32.8 \%$ ) on top of copper (Figure 7c), in addition to a minor gold nanoclustering (Figure 7d). 


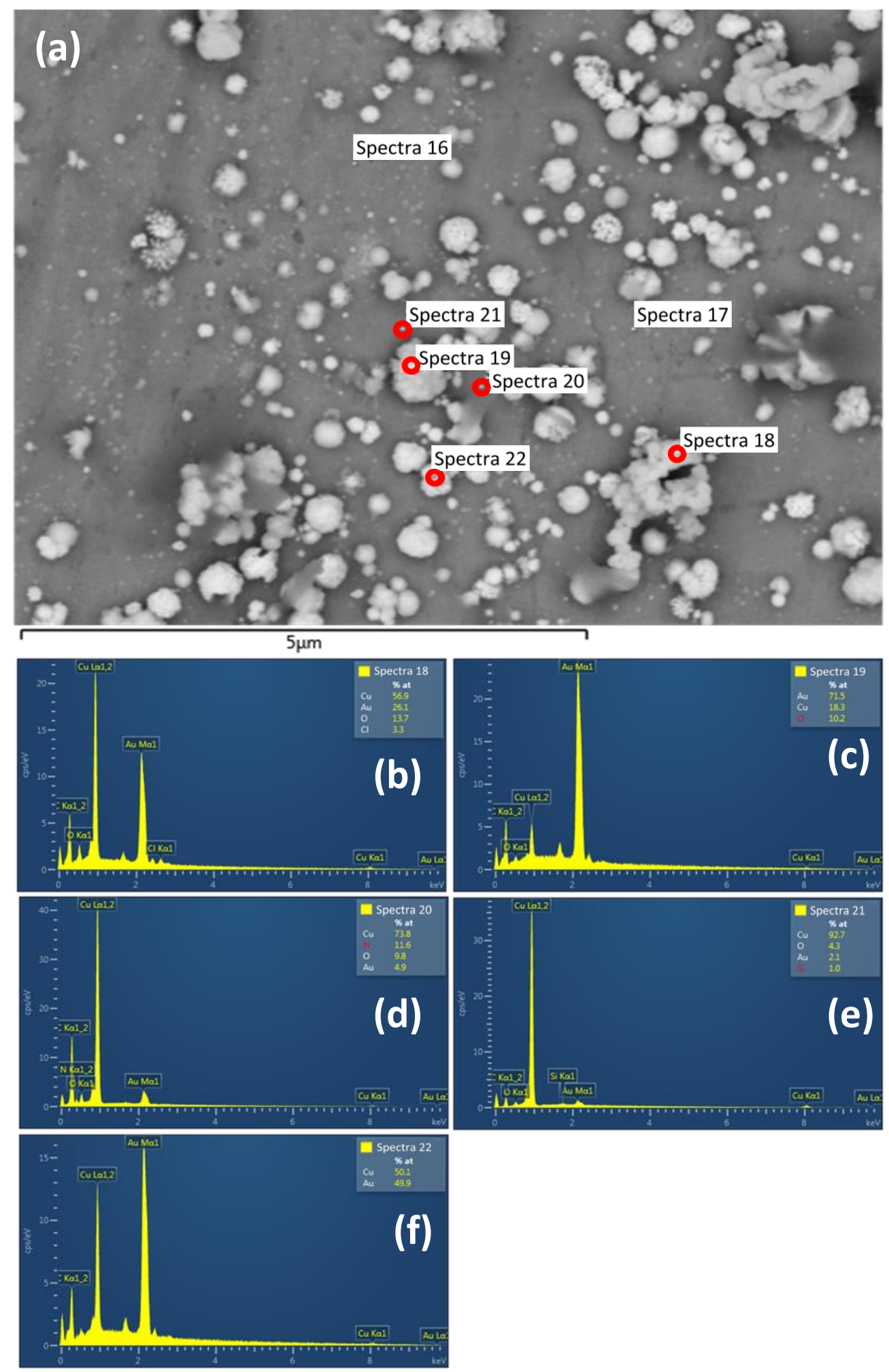

Figure 6. SEM image (a) and EDS elemental spectra (b-f) of the nonfingerprint area of treated copper sheet with $4-\mathrm{O}_{2} \mathrm{NC}_{6} \mathrm{H}_{4} \mathrm{~N}_{2}{ }^{+} \mathrm{AuCl}_{4}{ }_{4}^{-}$. 

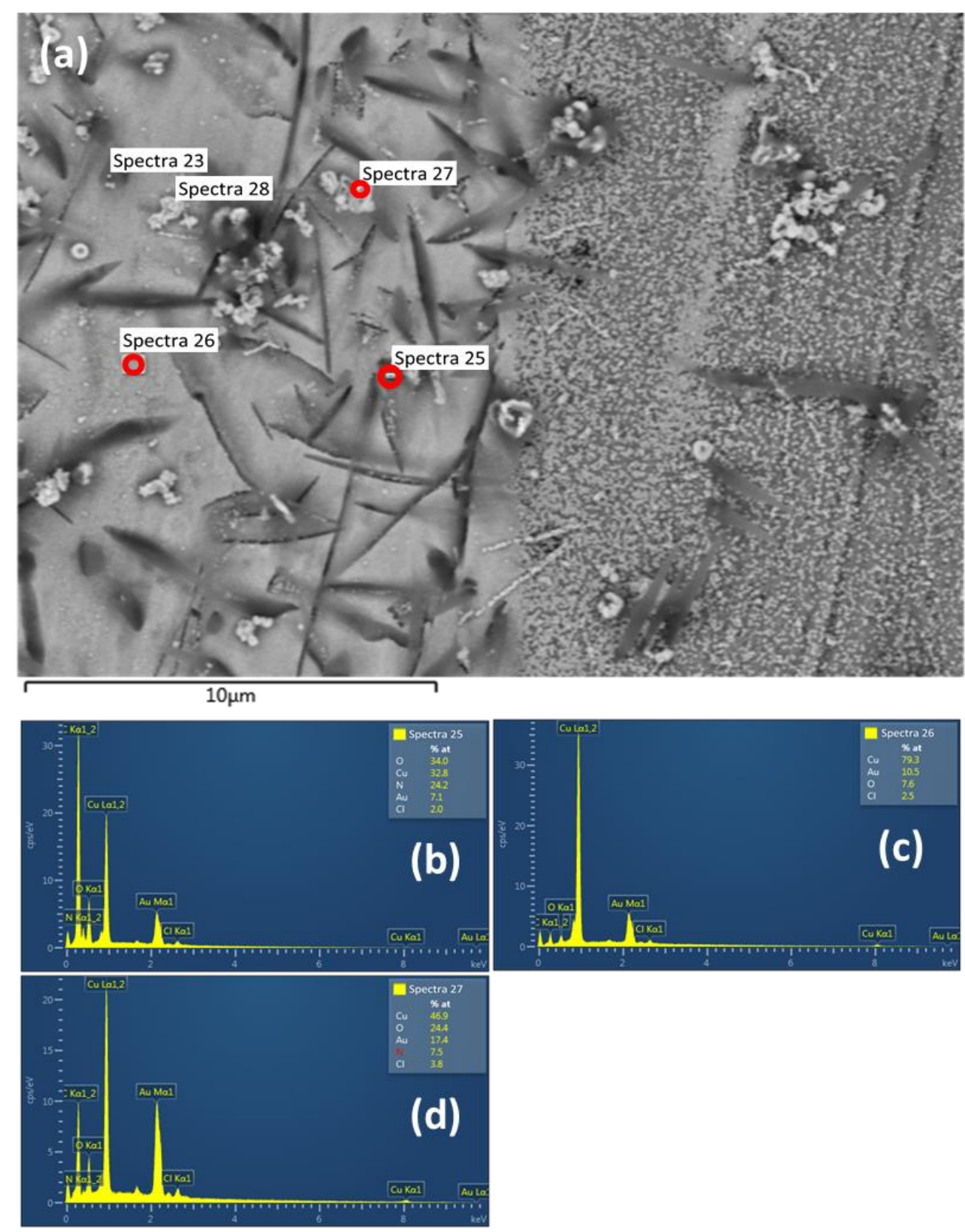

Figure 7. SEM image (a) and EDS elemental spectra (b, c, d) of the fingerprint area of treated copper sheet with $4-\mathrm{O}_{2} \mathrm{NC}_{6} \mathrm{H}_{4} \mathrm{~N}_{2}{ }^{+} \mathrm{AuCl}_{4}{ }^{-}$.

To sum up, Figure 8 proposes a mechanistic view of the reaction of $4-\mathrm{O}_{2} \mathrm{NC}_{6} \mathrm{H}_{4} \mathrm{~N}_{2}{ }^{+} \mathrm{AuCl}_{4}{ }^{-}$ aqueous solution with a copper sample without and with fingerprints after $1 \mathrm{~h}$ standby. After $1 \mathrm{~h}$ wait and quenching, the fingerprint and $4-\mathrm{O}_{2} \mathrm{NC}_{6} \mathrm{H}_{4} \mathrm{~N}_{2}{ }^{+} \mathrm{AuCl}_{4}{ }^{-}$layer merged into one with clear sign of $\mathrm{Cu}(\mathrm{II})$ of copper diffusing onto the upper layer via XPS measurements (Figure 8, right); 
this what explains the occurrence of dark, black marks (the color of $\mathrm{CuO}$ ). Initial sample preparation without fingerprints (Figure 8b, left) gives a slight change in the color of the copper coin, after $1 \mathrm{~h}$ wait and quenching, however without detection of $\mathrm{Cu}$ (II) diffusion and localized dark spots (see also Figure S2, top left coin). Obviously, it is the combination of the fingerprints and the aryldiazonium salt that permits the visualization of the latent fingerprints. Chloride ions in eccrine sweat are known to corrode copper and even noble metals after long contact (10 days) with fingerprints. ${ }^{33}$ However, for fast visualization, the fingerprints alone do not suffice since after $1 \mathrm{~h}$; the fingerprint on 1 euro cent clean copper coin does not lead to the developed black lines as shown in Figure S4.

$\mathrm{NO}_{2}$-Aryldiazonium-AuCl

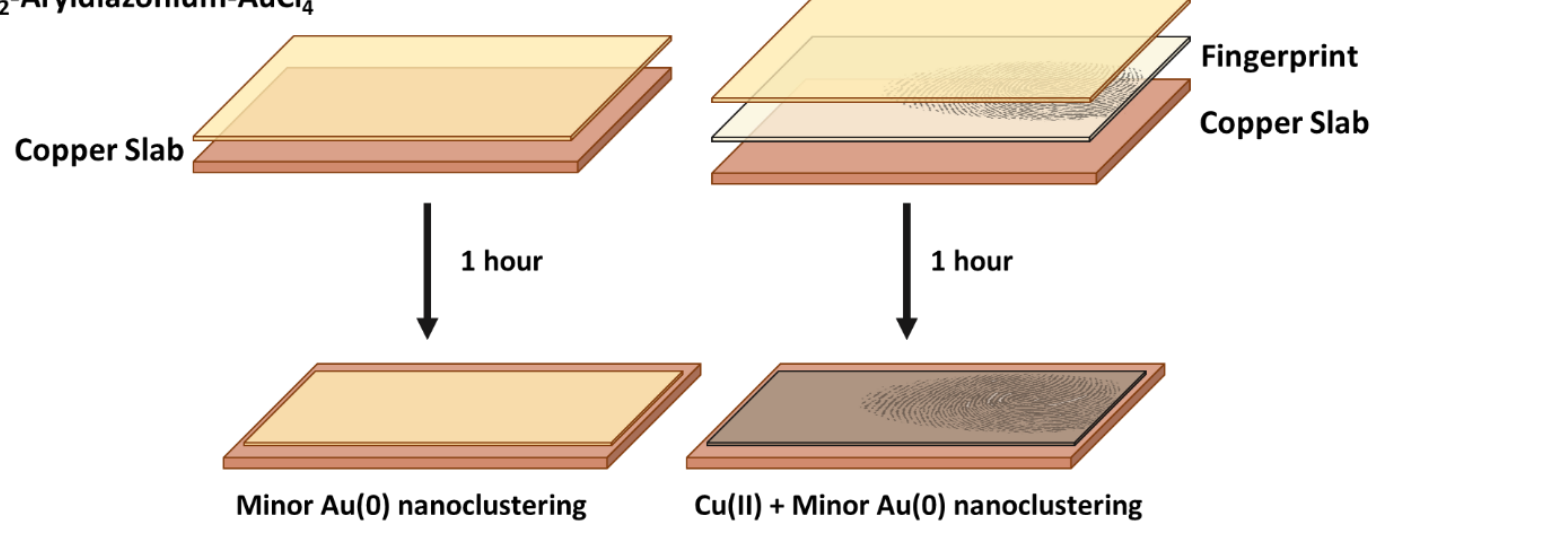

Figure 8. Reaction of clean and fingerprint-coated copper samples with nitrobenzenediazonium tetrachloroaurate aqueous solution.

\section{Summary and Conclusions}

4-nitrobenzenediazonium tetrachloroaurate, $4-\mathrm{O}_{2} \mathrm{NC}_{6} \mathrm{H}_{4} \mathrm{~N}_{2}{ }^{+} \mathrm{AuCl}_{4}{ }^{-}$, was reacted on copper coins and sheets. The samples were first treated with the salt solution for 30, 60, 90, and $120 \mathrm{~min}$ 
without fingerprints application and subsequently analyzed with XPS. Treated copper samples produced $\mathrm{N}_{2}$ bubbles on non-fingerprint side and dark lines on fingerprint side. Following this result, a second XPS analysis of another batch of sample surfaces of $\mathrm{Cu}$ treated with both fingerprints and salt solution were performed. There are strong evidences of the reduction of $\mathrm{Au}(\mathrm{III})$ to $\mathrm{Au}(0)$ and diazonium cation to aryl functional groups on copper samples. In copper sample analysis, there is an indication of copper leaching through the fingerprint and gold/aryl coating. Copper is leached as $\mathrm{CuO}$, hence the black color of the demonstrated fingerprints. These observations indicate the potential application of $\mathrm{Au}(\mathrm{III})$ diazonium salt solution for a fast development of latent fingerprints.

This work highlights the unique combination of XPS and diazonium chemistry to study the development of latent fingerprints without any external stimuli, for example without any applied potential or heat as reported previously in the literature. Diazonium gold(III) salts offer fast application of fingerprints detection and development and can be further applied on other metal surfaces that have reducing property.

\section{Acknowledgements}

AAM acknowledges the University of Sharjah support of SEED grant VC-GRC-SR-83-2015, competitive grants 160-2142-029-P and 150-2142-017-P, Organometallic Research Group grant RISE-046-2016 and Functionalized Nanomaterials Synthesis Lab grant 151-0039. SAA thanks The General Department of Forensic Science and Criminology (Dubai Police HQ, Dubai) for financial support to visit ICMPE and perform surface modification and XPS analyses.

\section{Supporting Information}

The Figures show mounting copper coins on sample holder, and selected areas analyzed by XPS. Tables reporting XPS-determined compositions of copper coins after reaction diazonium salts. This material is available free of charge via the Internet at http://pubs.acs.org. 


\section{References}

1. Bécue, A. Emerging fields in fingermark (meta)detection - a critical review. Anal. Methods 2016, 8, 7983-8003.

2. Cadd, S. J.; Mota, L.; Werkman, D.; Islam, M.; Zuidberg, M.; de Puit, M. Extraction of fatty compounds from fingerprints for GCMS analysis. Anal. Methods 2015, 7, 1123-1132.

3. Schwoeble, A. J.; Strohmeier, B. R.; Bunker, K. L; McAllister, D. R.; Marquis, J. P.; Piasecki, J. D.; McAllister, N. M. Application of X-ray photoelectron spectroscopy (XPS) for the surface characterization of Gunshot Residue (GSR). Microscopy Today 2011, 19(2), 40-45.

4. Fouetio Kengne, B.-A.; Karmakar, S.; Kaura, M.; Sai, V. V. R.; Corti, G.; Niraula, I. B.; Larin, A.; Hall, J.; Sowell, D.; Hrdlicka, P. J.; et al. Self-assembled monolayers of thiols adsorbed on $\mathrm{Au} / \mathrm{ZnO}$-functionalized silica nanosprings: Photoelectron spectroscopy-analysis and detection of vaporized explosives. ACS Appl. Mater. Interfaces 2014, 6, 13355-13366.

5. Sharma, J.; Beard B. C. (1990) Fundamentals of X-ray Photoelectron Spectroscopy (XPS) and Its Applications to Explosives and Propellants. In: Bulusu S.N. (eds) Chemistry and Physics of Energetic Materials. NATO ASI Series (Series C: Mathematical and Physical Sciences), vol 309. Springer, Dordrecht.

6. Sui, H.; Hao, X.; Luo, Y.; Xu, J.; Zhong, F.; Xu, R. Determination of the radiation resistance order of high explosives by the two dimensional correlation X-ray photoelectron spectroscopy. Nucl. Instrum. Methods Phys. Res. B 2017, 406, 496-500.

7. Mahoney, C. M.; Fahey, A. J.; Steffens, K. L.; Benner, B. A.; Jr.; Lareau, R. T. Characterization of composition $\mathrm{C} 4$ explosives using time-of-flight secondary ion mass spectrometry and X-ray photoelectron spectroscopy. Anal. Chem. 2010, 82(17), 7237-7248.

8. Liyanage, T.; Rael, A.; Shaffer, S.; Zaidi, S.; Goodpaster, J. V.; Sardar, R. Fabrication of a selfassembled and flexible SERS nanosensor for explosive detection at parts-perquadrillion levels from fingerprints. Analyst 2018, 143, 2012-2022.

9. Watts, J, F. The potential for the application of X-ray photoelectron spectroscopy in forensic science. Surf. Interface Anal. 2010, 42, 358-362.

10. Ricci, C.; Bleay, S.; Kazarian, S. G. Spectroscopic imaging of latent fingermarks collected with the aid of a gelatin tape. Anal. Chem. 2007, 79(15), 5771-5776.

11. Chen, T.; Schultz, Z. D.; Levin, I. W. Infrared spectroscopic imaging of latent fingerprints and associated forensic evidence. Analyst 2009, 134, 1902-1904.

12. Bailey, M. J.; Bright, N. J.; Croxton, R. S.; Francese, S.; Ferguson, L. S.; Hinder, S.; Jickells, S.; et al. Chemical characterization of latent fingerprints by matrix-assisted laser desorption ionization, time-of-flight secondary ion mass spectrometry, mega electron volt secondary mass spectrometry, gas chromatography/mass spectrometry, X-ray photoelectron spectroscopy, and attenuated total reflection fourier transform infrared spectroscopic imaging: an intercomparison. Anal. Chem. 2012, 84, 8514-8523.

13. Cheng, Y. H.; Zhang, Y.; Chau, S. L.; Lai, S. K. M.; Tang, H. W.; Ng, K. M. Enhancement of image contrast, stability, and SALDI-MS detection sensitivity for latent fingerprint analysis by tuning the composition of silver-gold nanoalloys. ACS Appl. Mater. Interfaces 2016, 8, 2966829675.

14. Kim, Y. J.; Jung, H. S.; Lim, J.; Ryu,S. J.; Lee, J. K. Rapid imaging of latent fingerprints using biocompatible fluorescent silica nanoparticles. Langmuir 2016, 32, 8077-8083. 
15. Wang, M.; Zhu, Y.; Mao, C. Synthesis of NIR-responsive NaYF4:Yb,Er upconversion fluorescent nanoparticles using an optimized solvothermal method and their applications in enhanced development of latent fingerprints on various smooth substrates. Langmuir 2015, 31, 7084-7090.

16. Zheng, L. N.; Ma, R. L.; Li, Q.; Sang, Y. B.; Wang, H. L.; Wang, B.; Yan, Q. Q.; et al. Elemental analysis and imaging of sunscreen fingermarks by X-ray fluorescence. Anal. Bioanal. Chem. 2019, 411, 4151-4157.

17. Boseley, R. E.; Dorakumbura, B. N.; Howard, D. L.; de Jonge, M. D.; Tobin, M. J.; Vongsvivut, J.; Ho, T. T. M.; et al. Revealing the elemental distribution within latent fingermarks using synchrotron sourced X-ray fluorescence microscopy. Anal. Chem. 2019, 91, 10622-10630.

18. Girard-Lauriault, P. L.; Gross, T.; Lippitz, A.; Unger, W. E. S. Chemical and elemental depth profiling of very thin organic layers by constant kinetic energy XPS: a new synchrotron XPS analysis strategy. Anal. Chem. 2012, 84, 5984-5991.

19. Viornery, C.; Chevolot, Y.; Le'onard, D.; Aronsson, B. O.; Pechy, P.; Mathieu, H. J.; Descouts, P.; et al. Surface modification of titanium with phosphonic acid to improve bone bonding: characterization by XPS and ToF-SIMS. Langmuir 2002, 18, 2582-2589.

20. Banerjee, J.; Bojan, V.; Pantano, C. G.; Kim, S. H. Effect of heat treatment on the surface chemical structure of glass: Oxygen speciation from in situ XPS analysis. J. Am. Ceram. Soc. 2018, 101, 644-656.

21. Ahmad, A. A. L.; Alawadhi, A. H.; Park, J.; Abdou, H. E.; Mohamed, A. A. Evaluation of diazonium gold(III) salts in forensic chemistry: Latent fingerprint development on metal surfaces. Forensic Chemistry 2019, 13, 100144.

22. Belanger, D.; Pinson, J. Electrografting: a powerful method for surface modification. Chem. Soc. Rev. 2011, 40, 3995-4048.

23. Bond, J. W. Visualization of latent fingerprint corrosion of metallic surfaces. J. Forensic Sci. 2008, 53, 812-822.

24. Bond, J. W.; Heidel, C. Visualization of latent fingerprint corrosion on a discharged brass shell casing, J. Forensic Sci. 2009, 54, 892-894.

25. Filimonov, V. D.; Trusova, M.; Postnikov, P.; Krasnokutskaya, E. A.; Lee, Y. M.; Yun Hwang, H. Y.; Kim, H.; et al. Unusually stable, versatile, and pure arenediazonium tosylates: their preparation, structures, and synthetic applicability. Org. Lett. 2008, 10(18), 3961-3964.

26. Bondarev, A.; Naumov, E.; Kassanova, A.; Krasnokutskaya, E.; Stankevich, K. S.; Filimonov, V. D. The first study of the thermal and storage stability of arenediazonium triflates comparing to 4nitrobenzenediazonium tosylate and tetrafluoroborate by calorimetric methods. Org. Process Res. Development. 2019, https://doi.org/10.1021/acs.oprd.9b00307

27. Orefuwa, S. A.; Ravanbakhsh, M.; Neal, S. N.; King, J. B.; Mohamed, A. A. Robust organometallic gold nanoparticles. Organometallics 2014, 33(2), 439-442.

28. Mohamed, A. A.; Neal, S. N.; Atallah, B.; AlBab, N.D.; Alawadhi, H. A.; Pajouhafsar, Y.; Abdou, H. E.; et al. Synthesis of gold organometallics at the nanoscale. J. Organomet. Chem. 2018, 877, 1-11.

29. Delamar, M.; Hitmi, R.; Pinson, J.; Saveant, J. M. Covalent modification of carbon surfaces by grafting of functionalized aryl radicals produced from electrochemical reduction of diazonium salts. J. Am. Chem. Soc., 1992, 114, 5883-5884. 
30. Lafi, A.; Shehadi, I.; Naggar, M.; Alawadhi, H.; Abdou, H. E.; Mohamed. A. A. Forensic Nanotechnology: Engineering Polyaniline Nanocomposites for Latent Fingerprints Development. J. Nanosci. Nanotechnol. 2017, 17(5), 2865-2872.

31. Biesinger, M.M. Advanced analysis of copper X-ray photoelectron spectra. Surf. Interface Anal. 2017, 49, 1325-1334.

32. NIST XPS database, https://srdata.nist.gov/xps/

33. Bond, J. W.; Phil, D. The thermodynamics of latent fingerprint corrosion of metal elements and alloys, J. Forensic Sci., 2008, 53, 1344-1352.

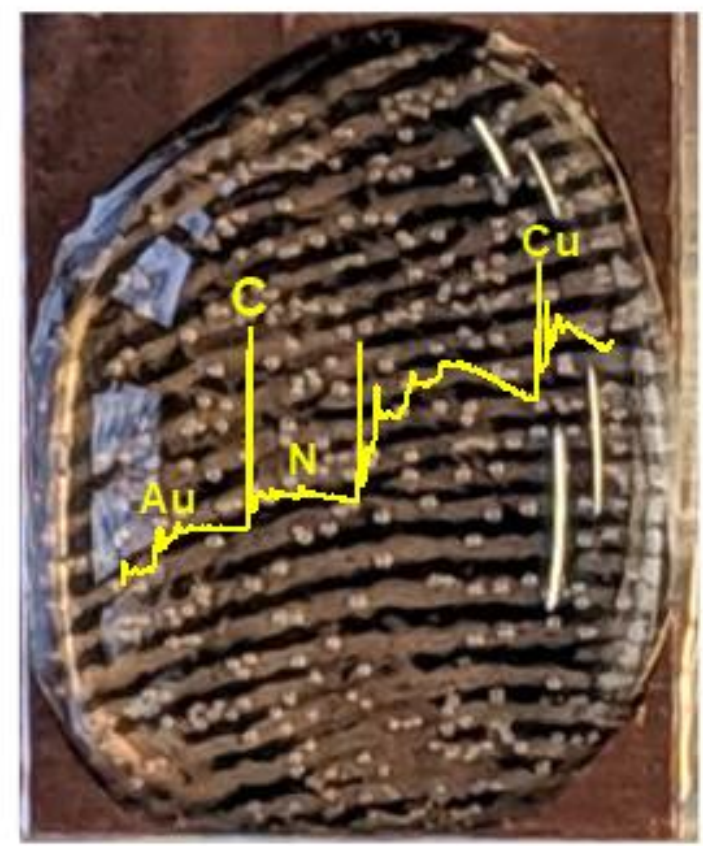

XPS analysis of fingerprint visualized with 4-nitrobenzenediazonium tetrachloroaurate salt 